・研究报告・

\title{
我国沿海棱鳀属鱼类的物种鉴定与系统发育
}

\author{
张 静 ${ }^{1,4}$ 李 渊 $^{2}$ 宋 娜 1 林龙山 ${ }^{2}$ 高天翔 $3^{*}$ \\ 1 (中国海洋大学水产学院, 山东青岛 266003) \\ 2 (国家海洋局第三海洋研究所海洋生物与生态实验室, 福建厦门 361005) \\ 3 (浙江海洋大学水产学院, 浙江舟山 316000) \\ 4 (集美大学水产学院, 福建厦门 361021)
}

\begin{abstract}
摘要: 利用DNA条形码技术对中国沿海分布的6种棱鳀属(Thryssa) 鱼类样品进行了物种鉴定, 并每种取 5 尾用于探 讨该属系统发育关系。结果显示: 棱鳀属鱼类的主要形态鉴别特征为上领骨伸达位置和第一鰓耙的下鰓耙数量。 在 $525 \mathrm{bp}$ 的目的片段上有 175 个变异位点, 其中简约信息位点 172 个, 单一信息位点 3 个, 无插入缺失现象, 转换数 为 182 , 颠换数为 57 。 $\mathrm{A}+\mathrm{T}$ 含量明显高于 $\mathrm{G}+\mathrm{C}$ 含量, 并且表现出明显的反 $\mathrm{G}$ 偏倚。结合 GenBank中相关的同源序列 进行比较发现, 所有序列明显分为 10 个组群, 表明已提交的棱鳀属鱼类COI基因序列中仍存在一定的问题。从各组 群间的遗传距离和氨基酸遗传差异水平可以看出，10个组群应为不同的有效种, 但是否存在隐存种还有待于进一 步确定。从NJ树上可以看出, 长领棱鳀(T. setirostris)是最先分化出的物种, 保持着最原始的特征, 而中领棱鳀 $(T$. mystax) 与黄吻棱鳀( T. vitrirostris) 聚类到一起，二者间存在共享单倍型。棱鳀属鱼类最早分化于中新世早期。在今 后的研究中仍需要结合更多的分子标记对中领棱鳀和黄吻棱鳀的分类地位作进一步的探讨。
\end{abstract}

关键词: 棱鳀属; 系统发育关系; DNA条形码; 遗传距离; 形态学

\section{Species identification and phylogenetic relationship of Thryssa species in the coastal waters of China}

\author{
Jing Zhang ${ }^{1,4}$, Yuan $\mathrm{Li}^{2}$, Na Song ${ }^{1}$, Longshan $\mathrm{Lin}^{2}$, Tianxiang $\mathrm{Gao}^{3 *}$ \\ 1 Fisheries College, Ocean University of China, Qingdao, Shandong 266003 \\ 2 Laboratory of Marine Biology and Ecology, Third Institute of Oceanography, State Oceanic Administration, Xiamen, \\ Fujian 361005 \\ 3 School of Fishery, Zhejiang Ocean University, Zhoushan, Zhejiang 316000 \\ 4 Fisheries College, Jimei University, Xiamen, Fujian 361021
}

\begin{abstract}
Six Thryssa species were collected from Chinese coastal waters for morphological description and phylogenetic relationships analysis. Results indicated that the position of maxillary extend and number of lower gill rake in the first gill rake were the main morphological characteristics for the identification of six Thryssa species. Mitochondrial COI gene fragments were amplified and sequenced for thirty individuals of Thryssa species. A 525 bp sequence was obtained, containing 175 variable sites, which determines 172 parsimony informative sites, 3 singleton sites, no indels/deletions, 182 transitions, and 57 transversions. An obvious anti-G biasness was noted from the base composition of $A$ and $T$ higher than that of $\mathrm{G}$ and $\mathrm{C}$. Comparing homologous sequences from GenBank with our study validates that there are variations among Thryssa species based on the COI sequence. Moreover ten absolute groups were also identified in all sequences based on genetic differences in amino acids and genetic distances between groups. However, this requires further investigation to determine whether there are uncovered cryptic species. The $\mathrm{NJ}$ tree indicated that $T$. setirostris was the first species derived from the genus, and sequences of T. mystax were disorderly clustered with that of T. vitrirostris. The divergence date of Thryssa species presented here is early Miocene. It is suggested that more molecular markers be needed to clarify variations in T. mystax and T. vitrirostris in the future.
\end{abstract}

收稿日期: 2016-03-22; 接受日期: 2016-05-13

基金项目: 公益性行业(农业)科研专项(201303048)、全球变化与海气相互作用专项(GASI-02-SCS-YSWspr, GASI-02-SCS-YSWaut)和国家海洋局海洋 国际合作及履约项目(2200207)

* 通讯作者 Author for correspondence. E-mail: gaotianxiang0611@163.com 
Key words: Thryssa; phylogenetic relationship; DNA barcoding; genetic distance; morphology

棱鳀属(Thryssa) 鱼类隶属于鲱形目、鳀科, 广 泛分布于印度-太平洋(朱元鼎等, 1984; 张世义, 2001; 孙典荣和陈铮，2013)。作为近海中上层小型 鱼类, 其生长迅速、性成熟较快、资源恢复能力较 强, 在海洋生态系统能量流动与转换中起着承上启 下的作用, 是海洋食物网中的关键种 (贾晓平等, 2004)。迄今为止, 已报道棱鳀属鱼类有 24 种 (Whitehead et al, 1988), 在中国近海报道分布的仅 有 6 种, 分别为赤鼻棱鳀 (T. kammalensis)、中领棱鳀 (T. mystax)、杜氏棱鳀( T. dussumieri)、长领棱鳀 $(T$. setirostris)、汉氏棱鳀(T. hamiltonii) 和黄吻棱鳀 $(T$. vitrirostris)。随着大黄鱼(Larimichthys crocea)、小 黄鱼(L. polyactis)、带鱼(Trichiurus japonicus)等传统 经济鱼类资源的相继衰退, 过去不受重视的棱鳀属 等小型鱼类逐渐成为了重要的捕捞对象。目前有关 棱鳀属鱼类的研究较少, 主要集中在分类学 (朱元 鼎等, 1984; 张世义, 2001; 孙典荣和陈铮, 2013)、渔 业生物学( 郭学武和唐启升, 2000; 李忠义等, 2007)、资源量的分布与利用(Whitehead et al, 1988) 和系统发育(马春艳等, 2010; Lavoué et al, 2010; Bloom \& Lovejoy, 2012)等方面。

依据传统形态分类方法, 中国近海棱鳀属鱼类 的主要外部鉴别特征为上领骨末端伸达的位置(朱 元鼎等, 1984; 张世义, 2001; 孙典荣和陈铮, 2013)。 例如: 上领骨末端伸达鳃盖或鳃孔的为赤鼻棱鳀和 汉氏棱鳀, 其中吻较长且呈赤红色的为赤鼻棱鳀; 上领骨末端伸达胸鯺基部的为中领棱鳀和黄吻棱 鳀, 其中下鳃耙数少于 17 的为中领棱鳀; 上领骨末 端超过胸鯺基部几达腹鯺起点的为杜氏棱鳀; 上领 骨末端伸达肛门的为长领棱鳀。其中, 争议最大的 为中领棱鳀和黄吻棱鳀。马春艳等(2010)利用线粒 体16S rRNA基因序列探讨了棱鳀属的系统进化关 系, 认为中领棱鳀和黄吻棱鳀可能为同一种, 这一 结论明显不同于传统形态学的分类结果。

DNA条形码即利用线粒体COI基因片段序列作 为物种快速鉴定的标记, 并以此建立DNA序列和生 物物种之间的一一对应关系(Hebert et al, 2003)。线 粒体COI基因进化速率低、保守性高, 种内的 COI 序列变异很小, 而种间的COI序列差异显著, 能明
显区分不同的物种，并适用于种以上水平的系统进 化研究(Hebert et al, 2003; Zhang \& Hanner, 2012; Zhang et al, 2013)。如今, 该技术已被广泛应用于种 类鉴别(Hebert et al, 2003; 李洣等, 2013)、新记录种 或新种的发现(Gao et al, 2011; 李渊等, 2014)、隐存 种发掘(Chen et al, 2015; Shen et al, 2016a)、鱼卵仔 稚鱼鉴定(Ko et al, 2012; 周美玉等, 2015)、水产品 检测(Shen et al, 2016b)等。迄今为止, 尚未见利用 COI基因片段对棱鳀属鱼类进行种类鉴别和系统发 育的相关研究。因此, 本研究采集了中国沿海分布 的棱鳀属鱼类, 利用条形码技术对其进行种类鉴 定, 并结合GenBank中该属相同拉丁学名下的所有 COI基因序列进行系统发育研究, 纠正出现的错误 序列, 以期为今后棱鳀属鱼类的分类和遗传学研究 提供依据。

\section{1 材料与方法}

\section{1 实验材料}

于2009-2014年间采集中国沿海棱鳀属鱼类， 在确定种类鉴别无误后, 每个物种选取 1 个地理群 体用于后续相关研究(表1), 目前所有样品均保存于 中国海洋大学渔业生态学实验室。

\section{2 实验方法}

\subsection{1 形态学}

依据朱元鼎等(1984)的分类鉴别方法对采集的 棱鳀属鱼类进行鉴定。对其第一鳃耙下鳃耙、背鯺、 胸鯺和壂鯺的鯺棘和鯺条等可数性状进行计数, 并 对体长 $(\mathrm{A})$ 、体高 $(\mathrm{B})$ 、头长 $(\mathrm{C})$ 、吻长 $(\mathrm{D})$ 、眼径 $(\mathrm{E})$ 、 尾柄长 $(\mathrm{F})$ 和尾柄高 $(\mathrm{G})$ 等可量性状进行测量, 精确 到 $0.1 \mathrm{~mm}$ 。

\subsection{2 分子遗传学}

取适量肌肉组织, 采用海洋动物组织DNA提取 试剂盒提取基因组DNA, $4^{\circ} \mathrm{C}$ 保存备用。用于扩增 COI片段的引物为(Hebert et al，2003): F1: 5'-TCAACCAACCACAAAGACATTGGCAC-3'; R1: 5'-TAGACTTCTGGGTGGCCAAAGAATCA-3'。 $\mathrm{PCR}$ 反应体系为 $25 \mu \mathrm{L}$ (李渊等, 2013), 包括 $1.25 \mathrm{U}$ Taq DNA聚合酶, 各种反应组分的终浓度为 $200 \mathrm{nM}$ 的正反向引物; $200 \mu \mathrm{M}$ 的 dNTP, $10 \mathrm{mM}$ Tris $\mathrm{pH} 8.3$, 
表1 研究所用棱鳀属鱼类样品和相关序列信息

Table 1 Information of Thryssa samples and sequences in this study

\begin{tabular}{|c|c|c|c|c|}
\hline \multirow{3}{*}{$\begin{array}{l}\text { 种名 } \\
\text { Species }\end{array}$} & \multicolumn{3}{|c|}{ 本研究 This study } & \multirow{3}{*}{$\begin{array}{l}\text { 引用序列号 } \\
\text { - Accession no. }\end{array}$} \\
\hline & 地点 & 采样时间 & 编号 & \\
\hline & Sampling sites & Sampling time & Number & \\
\hline \multirow{4}{*}{$\begin{array}{l}\text { 赤鼻棱鳀 } \\
\text { T. kammalensis } \\
\text { 中领棱鳀 }\end{array}$} & 福建省晋江市 & \multirow[t]{2}{*}{2014.3} & \multirow[t]{2}{*}{ CB1-CB5 } & EF607590-607596, JN813096, JQ738607-738609, KF951618, \\
\hline & Jinjiang, Fujian & & & KP260469, KP260453 \\
\hline & 山东省东营市 & \multirow[t]{2}{*}{2009.10} & \multirow[t]{2}{*}{ ZH1-ZH5 } & - - \\
\hline & Dongying, Shandong & & & \\
\hline 杜氏棱鳀 & 福建省漳州市 & \multirow[t]{2}{*}{2013.5} & \multirow[t]{2}{*}{ DS1-DS5 } & \multirow[t]{2}{*}{ JX983287-983289 } \\
\hline T. dussumieri & Zhangzhou, Fujian & & & \\
\hline 长领棱鳀 & 福建省泉州市 & \multirow[t]{2}{*}{2013.5} & \multirow[t]{2}{*}{$\mathrm{CH} 1-\mathrm{CH} 5$} & \multirow[t]{2}{*}{ EF607597-607599, EU541324, JF494684-494688 } \\
\hline T. setirostris & Quanzhou, Fujian & & & \\
\hline 汉氏棱鳀 & 福建省晋江市 & \multirow[t]{2}{*}{2013.11} & \multirow[t]{2}{*}{ HS1-HS5 } & \multirow[t]{2}{*}{ EF607588, EF607589, JQ681498, EU148567-148570 } \\
\hline T. hamiltonii & Jinjiang, Fujian & & & \\
\hline 黄吻棱鳀 & 广东省江门市 & \multirow[t]{2}{*}{2013.3} & \multirow[t]{2}{*}{ HW1-HW5 } & \multirow[t]{2}{*}{ JF494689-494693 } \\
\hline T. vitrirostris & Jiangmen, Guangdong & & & \\
\hline
\end{tabular}

$50 \mathrm{mM} \mathrm{KCl}$ 和 $1.5 \mathrm{mM} \mathrm{MgCl}$ 。 反应条件为: $94^{\circ} \mathrm{C}$ 预 变性 $3 \mathrm{~min} ; 94^{\circ} \mathrm{C}$ 变性 $45 \mathrm{~s}, 52^{\circ} \mathrm{C}$ 退火 $45 \mathrm{~s}, 72^{\circ} \mathrm{C}$ 延伸 $45 \mathrm{~s}, 30$ 个循环; $72^{\circ} \mathrm{C}$ 延伸 $10 \mathrm{~min}$ 。以上反应均设阴 性对照以排除DNA污染的情况。取 $3 \mu \mathrm{L}$ PCR扩增产 物进行 $1 \%$ 琼脂糖凝胶电泳检测 $(\mathrm{U}=5 \mathrm{~V} / \mathrm{cm})$, 对符 合测序浓度的PCR产物进行纯化回收, 并送生物公 司进行双向测序。

依据外部形态特征对中领棱鳀和黄吻棱鳀进 行初步分类, 但由于二者形态上的相似性, 很容易 将其混淆。因此, 本研究对采集的中领棱鳀(东营、 南通、宁德、晋江、泉州、九龙江口和三娘湾)和黄 吻棱鳀(三沙湾和江门)所有样本的COI基因片段进 行双向测序。对鉴定无误的种类各选取 5 尾用于后 续的分子遗传学研究。

\section{3 数据处理}

将测得的目的片段序列用DNAStar软件包中的 Seqman软件进行比对, 并辅以人工校正。下载 GenBank中6种棱鳀属鱼类的所有 COI同源序列进 行比对分析。以斑䱕(Clupandon punctatus)和日本鳀 (Engraulis japonicus) 为外群, 基于 $\mathrm{K} 2 \mathrm{P}$ 模型并利用 MEGA 4.0软件构建 NJ系统发育树, 并计算组群内和 组群间的遗传距离。由于缺乏棱鳀属鱼类的化石记 录, 无法确定棱鳀属鱼类准确的核苷酸替换速率, 对 $\mathrm{COI}$ 基因片段采用 $1.2 \%$ /百万年的核苷酸分歧速率来 估算各物种间的分化年代(Bermingham et al, 1997)。

\section{2 结果}

对采集到的6种棱鳀属鱼类的主要形态特征进 行测量(表2), 样本体长范围为61-153 mm。除上领
骨伸达位置作为该属的种类鉴别特征外，第一鳃耙 的下鳃耙数同样可以作为种类鉴别的重要依据。其 中赤鼻棱鳀的下鳃耙数最多(27-31), 其次为黄吻棱 鳀(20-22), 之后分别为杜氏棱鳀(17-19)、中领棱鳀 (15-17)、汉氏棱鳀(12-15), 而长领棱鳀的下鳃耙数 最少 $(8-10)$ 。背鯺、臀鯺和胸鯺等可数性状均存在 一定的数量交叉。为消除样本因体长不同而产生的 差异, 使用标准化方法对样本的可度量特征进行标 准化(表2), 结果显示, 5 组标准化后的数据间同样存 在一定的重叠, 不能很好地区分开6种棱鳀属鱼类。 由此看出, 棱鳀属鱼类的种类鉴别主要依靠上领骨 伸达的位置和第一鳃耙的下鳃耙数, 其余形态特征 可作为参考补充。

依据下鳃耙数的不同对黄吻棱鳀和中领棱鳀 进行初步分类, 统计结果显示, 黄吻棱鳀下鳃耙数 范围为 20-22, 共 50尾; 中领棱鳀下鳃耙数范围为 15-17, 共128尾。对所有样品的COI序列进行测序, 获得 $655 \mathrm{bp}$ 的目的片段。在测得的 32 条黄吻棱鳀 COI序列中, 获得 7 个单倍型, 在测得的 128 条中领 棱鳀COI序列中, 获得 23 个单倍型, 二者间共享 4 个 单倍型。对所有 160 条序列进行比较, 发现存在 27 个变异位点, 但不存在能将二者完全分开的特殊位 点; 基于黄吻棱鳀和中领棱鳀所有单倍型构建邻接 系统发育树, 可以看出所有单倍型广泛地分布在系 统树上, 未发现与物种单独对应的谱系结构(图1); 二者之间的遗传距离为 0.004 , 明显低于种间差异 水平。由此可以看出COI片段并不能将中领棱鳀和 黄吻棱鳀完全分开。

棱鳀属鱼类每种随机取 5 尾, 并结合 GenBank 


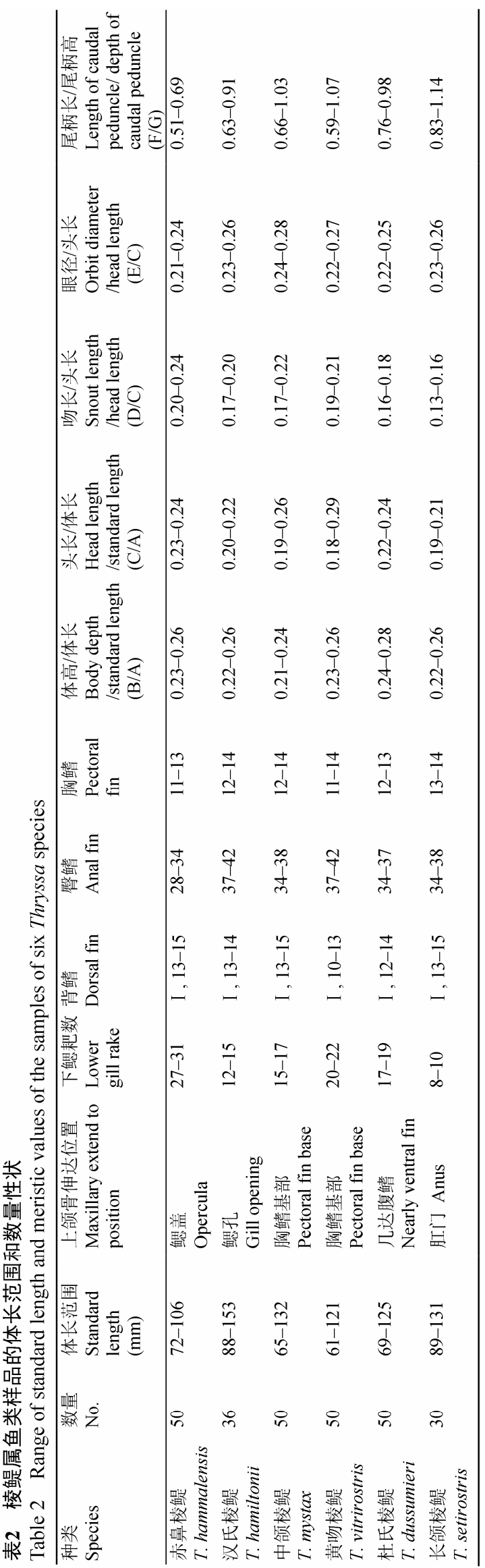

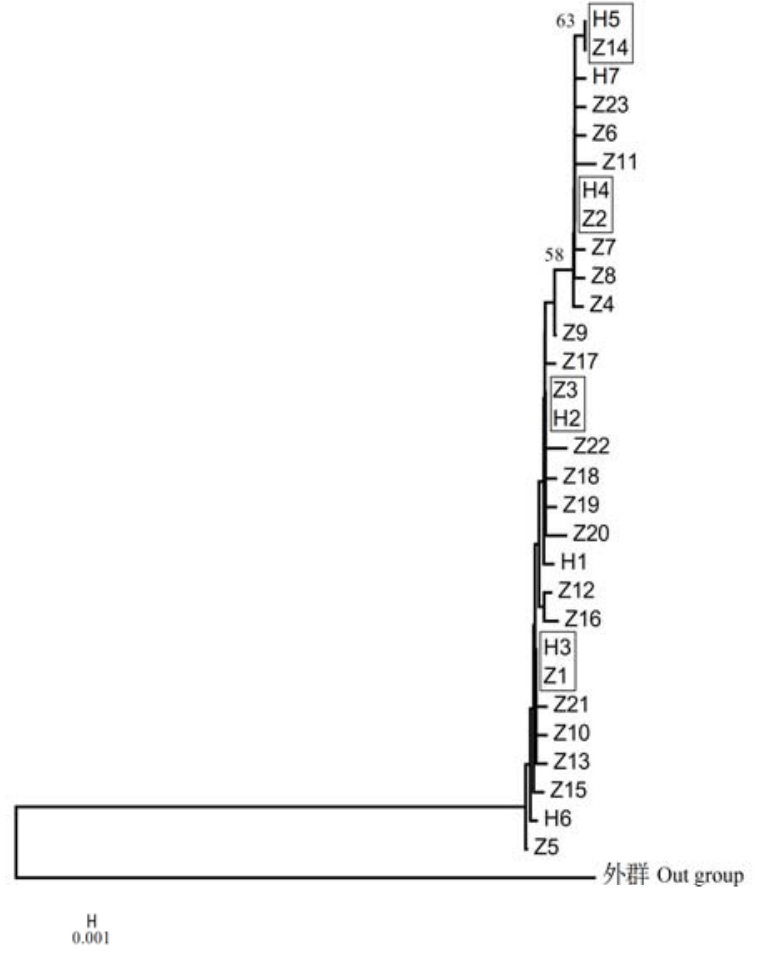

图1 基于单倍型构建黄吻棱鳀和中领棱鳀的邻接系统发育 树(方框内为共享单倍型)

Fig. 1 Phylogenetic tree of Thryssa vitrirostris and T. mystax based on all haplotypes. Shared haplotypes are in the box.

中下载的该属相关同源序列共 68 条进行比较分析, 得到目的片段长度为 $525 \mathrm{bp}$ 。所有位点中变异位点 175 个，简约信息位点 172 个，单一信息位点 3 个, 无 插入缺失现象。转换数为 182 , 颠换数为 57 , 转换/ 颠换比为 3.19 , 表明该基因的序列突变还未达到饱 和。各物种的碱基组成无明显差异, $\mathrm{T} 、 \mathrm{C} 、 \mathrm{~A} 、 \mathrm{G}$ 的 平均含量分别为 $29.9 \% 、 26.1 \% 、 25.5 \% 、 18.5 \%$, 表 现出明显的反 $\mathrm{G}$ 偏倚(表3)。在棱鳀属鱼类测得的序 列中，共检测到12个单倍型(表3)，其中赤鼻棱鳀、 杜氏棱鳀、汉氏棱鳀和长领棱鳀分别独享各自单倍 型，而中领棱鳀和黄吻棱鳀间共享 2 个单倍型。

以斑䰻和日本鳀为外群，构建邻接系统发育树 (图2)。从系统发育树上可以看到, 所有序列可聚类 成 10 个组群。其中组群 1 有 13 条序列, 为赤鼻棱鳀; 组群 2 有 10 条序列, 为黄吻棱鳀和中领棱鳀; 组群 3 有 1 条序列; 组群 4 有 6 条序列; 组群 5 有 7 条序列, 为 长领棱鳀; 组群6有 4 条序列; 组群7有 3 条序列; 组 群 8 有 5 条序列, 为杜氏棱鳀; 组群 9 有 5 条序列; 组 群10有14条序列, 为汉氏棱鳀, 且各组群间的支持 
表3 6种棱鳀属鱼类线粒体COI片段的碱基组成及单倍型数量

Table 3 Base composition and number of haplotypes of mitochondrial COI gene segment in six Thryssa species

\begin{tabular}{|c|c|c|c|c|c|}
\hline \multirow[t]{2}{*}{$\begin{array}{l}\text { 种类 Species } \\
\end{array}$} & \multicolumn{4}{|c|}{ 碱基组成 Nucleotide composition (\%) } & \multirow{2}{*}{$\begin{array}{l}\text { 单倍型数量 } \\
\text { Number of haplotypes }\end{array}$} \\
\hline & $\mathrm{T}(\mathrm{U})$ & $\mathrm{C}$ & A & G & \\
\hline 赤鼻棱鳀 T. kammalensis & 31.6 & 25.3 & 25.5 & 17.5 & 1 \\
\hline 中领棱鳀 T. mystax & 30.3 & 26.1 & 26.1 & 17.5 & 2 \\
\hline 杜氏棱鳀 T. dussumieri & 28.4 & 26.2 & 26.6 & 18.8 & 2 \\
\hline 长领棱鳀 T. setirostris & 28.8 & 27.1 & 25.3 & 18.9 & 2 \\
\hline 汉氏棱鳀 T. hamiltonii & 30.3 & 25.1 & 25.0 & 19.6 & 2 \\
\hline 黄吻棱鳀 T. vitrirostris & 30.3 & 26.1 & 26.1 & 17.5 & 3 \\
\hline 平均 Average & 29.9 & 26.1 & 25.5 & 18.5 & - \\
\hline
\end{tabular}

表4 基于COI基因序列10个组群的组内、组间的遗传距离和分化时间(百万年)

Table 4 Genetic distances within and among groups, the divergence dates between ten groups based on COI gene

\begin{tabular}{lllllllllll}
\hline & $\begin{array}{llll}\text { 组群1 } \\
\text { Group 1 }\end{array}$ & $\begin{array}{l}\text { 组群2 } \\
\text { Group 2 }\end{array}$ & $\begin{array}{l}\text { 组群3 } \\
\text { Group 3 }\end{array}$ & $\begin{array}{l}\text { 组群4 } \\
\text { Group 4 }\end{array}$ & $\begin{array}{l}\text { 组群5 } \\
\text { Group 5 }\end{array}$ & $\begin{array}{l}\text { 组群6 } \\
\text { Group 6 }\end{array}$ & $\begin{array}{l}\text { 组群7 } \\
\text { Group 7 }\end{array}$ & $\begin{array}{l}\text { 组群8 } \\
\text { Group 8 }\end{array}$ & $\begin{array}{l}\text { 组群9 } \\
\text { Group 9 }\end{array}$ & $\begin{array}{l}\text { 组群10 } \\
\text { Group 10 }\end{array}$ \\
\hline 组群1 Group 1 & 0.001 & 2.83 & 2.75 & 13.58 & 15.75 & 15.25 & 15.33 & 15.08 & 13.92 & 14.50 \\
组群2 Group 2 & 0.034 & 0.001 & 4.00 & 14.42 & 15.17 & 14.00 & 14.42 & 15.00 & 15.33 & 15.83 \\
组群3 Group 3 & 0.033 & 0.048 & - & 13.58 & 14.50 & 14.92 & 16.75 & 16.17 & 14.83 & 15.50 \\
组群4 Group 4 & 0.163 & 0.173 & 0.163 & 0.004 & 15.50 & 16.08 & 17.33 & 14.75 & 16.25 & 16.33 \\
组群5 Group 5 & 0.189 & 0.182 & 0.174 & 0.186 & 0.002 & 16.83 & 17.83 & 15.83 & 15.42 & 17.00 \\
组群6 Group 6 & 0.183 & 0.168 & 0.179 & 0.193 & 0.202 & 0.001 & 12.25 & 15.50 & 15.50 & 16.33 \\
组群7 Group 7 & 0.184 & 0.173 & 0.201 & 0.208 & 0.214 & 0.147 & 0.003 & 14.25 & 15.92 & 16.17 \\
组群8 Group 8 & 0.181 & 0.180 & 0.194 & 0.177 & 0.190 & 0.186 & 0.171 & 0.003 & 17.42 & 16.08 \\
组群9 Group 9 & 0.167 & 0.184 & 0.178 & 0.195 & 0.185 & 0.186 & 0.191 & 0.209 & - & 13.67 \\
组群10 Group 10 & 0.174 & 0.190 & 0.186 & 0.196 & 0.204 & 0.196 & 0.194 & 0.193 & 0.164 & 0.001
\end{tabular}

分化时间在对角线上方，组间遗传距离在对角线下方，组内遗传距离在对角线上。

The divergence dates between groups are above the diagonal, genetic distances among groups are below the diagonal, and genetic distances within groups are on the diagonal

率均较高。除了 6 种棱鳀属鱼类外, 仍有 5 个组群存 在。其中组群3和组群4是以“T. setirostris”(长领棱鳀) 为学名进行提交的，组群6是以“T. hamiltonii” (汉氏 棱鳀)为学名进行提交的, 组群7是以“ $T$. dussumieri” (杜氏棱鳀)为学名进行提交的, 组群9是以“ $T$. vitrirostris” (黄吻棱鲳)为学名进行提交的。很明显这些 序列均不同于本研究对应物种的自测序列。

在COI蛋白质编码基因部分片段中，大部分的 突变是同义突变。在组群9内未发生碱基突变, 组群 1、4、5和 6 内各有 1 处碱基发生突变, 在组群7中有 2 处碱基发生突变, 组群 8 和组群 10 内有 3 处碱基发生 突变, 组群 2 内有 4 处碱基发生突变。在 $525 \mathrm{bp}$ 的目 的片段中, 共翻译氨基酸 175 个, 变异氨基酸数仅 为 3 个, 出现在组群 3 ( 2 个)与组群7 (1个)之间。除组 群 2 和组群 7 中有 1 处氨基酸序列发生变异外, 其余 组群内未检测到变异。

基于 $\mathrm{K} 2 \mathrm{P}$ 核苷酸最佳替换模型分别计算 10 个组 群内及组群间的遗传距离(表4)。组群 2 由中领棱鳀 和黄吻棱鳀混合组成, 组群内的遗传距离为 0.001 ,
明显低于种间的差异水平。除组群 2 外, 各组群内的 遗传距离范围为 $0-0.004$, 符合种内差异水平; 各组 群间的遗传距离为0.033-0.214, 明显超过一般物种 间的差异水平。同时可以看出种间遗传距离的最小 值与种内遗传距离的最大值无交叉现象，种间遗传 距离明显高于种内遗传距离, 暗示剩余的 9 个组群 可能是不同的物种。

由表4可以看出，各组群间的分化时间范围在 2.75-17.83百万年前, 其中组群 1 和组群 3 之间的分 化时间最短, 发生在上新世晚期; 组群 5 和组群 7 之 间分化时间最长，发生在中新世早期。

\section{3 讨论}

棱鳀属鱼类的外部形态相似, 结合之前的形态 学测量结果, 可以看出棱鳀属鱼类的主要鉴别特征 为上领骨伸达位置和第一鳃耙下鳃耙数量。由于鉴 定者参考的资料和主观原因，样品的鉴定往往会有 一定的出入。因此，有必要在形态鉴定的同时结合 DNA条形码技术对样品进行双重鉴定。本研究在基 


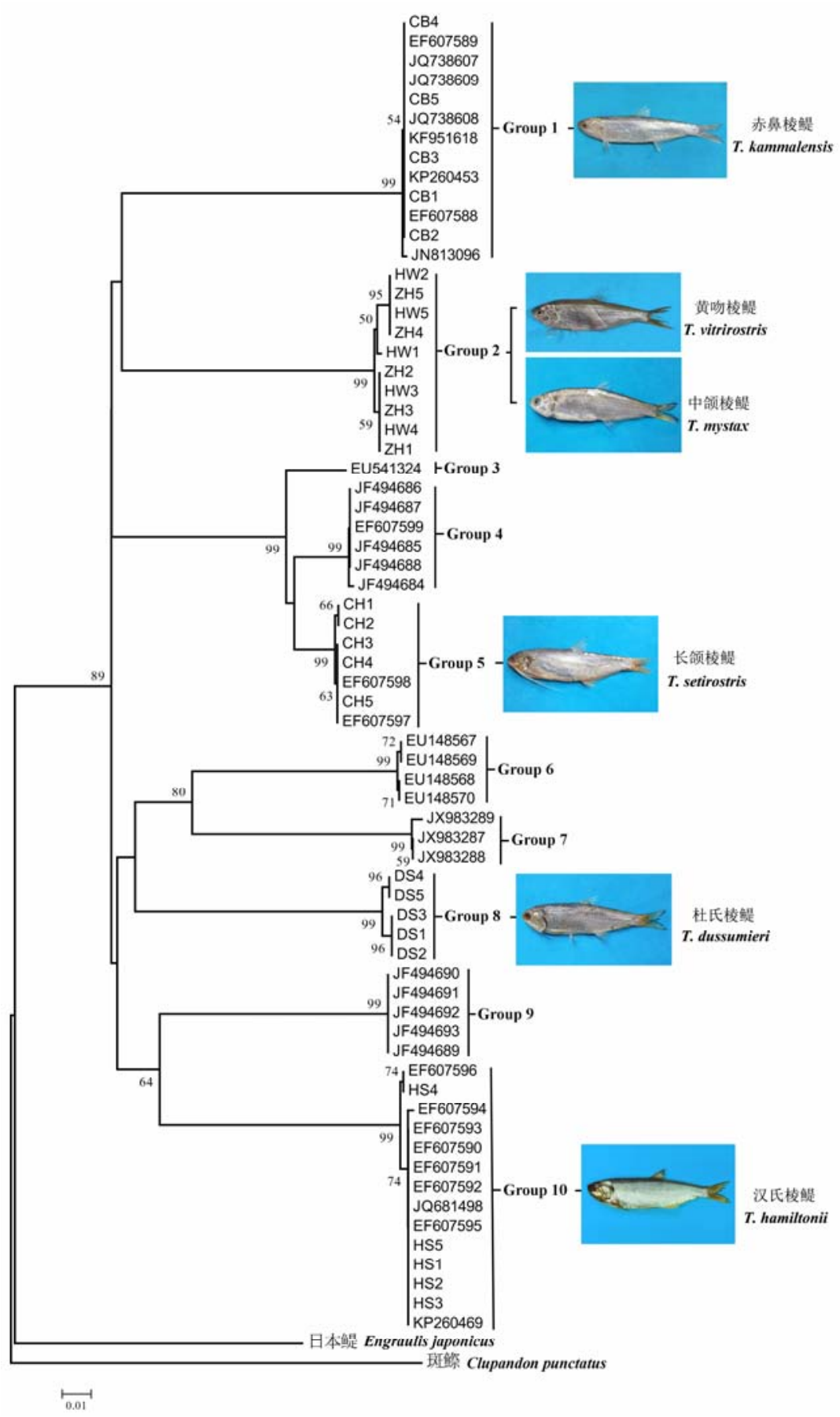

图2 构建棱鳀属鱼类邻接系统发育树

Fig. 2 Phylogenetic tree of Thryssa species based on neighbor-joining method

于形态特征和DNA条形码技术对我国沿海分布的 棱鳀属鱼类进行鉴别的同时, 结合GenBank中的相 关同源序列进行系统发育研究, 并对其中的错误序 列进行了纠正。

在碱基组成方面, 棱鳀属鱼类各种的 $\mathrm{A}+\mathrm{T}$ 含量 高于 $\mathrm{G}+\mathrm{C}$ 的含量 (表 3 ), 这一现象符合海水鱼类中
$\mathrm{A}+\mathrm{T}$ 含量偏高的规律(Ward et al, 2005)。在序列变异 方面, Hebert等(2003)认为在COI基因片段上，种内 差异一般都低于 $1 \%$, 甚少超过 $2 \%$; 而种间差异则 大于 $2 \%$ 。除组群 2 外, 剩余 9 个组群的组内和组间差 异水平均符合上述水平(表 4$)$, 暗示 9 个组群实为不 同的有效物种，且种间遗传分化明显(图2), 种间遗 
传距离平均值明显高于种内遗传距离平均值, 基本 符合种间与种内遗传距离的“10×”法则(Ward et al, 2005)。

从系统发育树上可以看出, 赤鼻棱鳀、黄吻棱 鳀和中领棱鳀、长领棱鳀、杜氏棱鳀和汉氏棱鳀分 别聚为一支, 达到种间差异水平, 而其余 5 个组群 间的遗传距离同样超过了种的界限(表4)。其中组群 3、4和5 (自测)中的序列均是以“T. setirostris” (长领 棱鳀) 为学名进行提交, 可以看出组群 3 和 4 明显不 属于长领棱鳀; 组群6是以“T. hamiltonii”(汉氏棱鳀) 为学名进行提交, 明显不同于自测汉氏棱鳀(组群 10); 组群9是以“T. vitirostris” (黄吻棱鳀)为学名进行 提交, 同样有别于自测的黄吻棱鳀。分别对组群3、4、 6 和9的序列在GenBank内重新Blast, 未发现有与之 匹配的序列。由于棱鳀属鱼类大部分种类的 COI基因 序列尚未报道, 且无实际样品对照, 因此无法确认 该4个组群是属于已报道而未发表相关序列信息的 种类，还是属于该属的隐存种。组群7是以“ $T . d u s-$ sumieri”(杜氏棱鳀)为学名进行提交, 明显不同于自 测杜氏棱鳀(组群8), 重新比对发现其与马拉巴棱鳀 (Thryssa malabarica) 的序列相匹配, 由于未获取到 马拉巴棱鳀的标本, 同样不能判断其准确性。

系统发育树还显示长领棱鳀属于最先分化出 的物种, 这一结果与形态学和 $16 \mathrm{~S}$ rRNA基因序列 分析结果不一致(马春艳等, 2010)。中领棱鳀与黄吻 棱鳀二者间的亲缘关系最近, 长领棱鳀与组群 3 和 组群4互为姐妹种, 杜氏棱鳀、汉氏棱鳀、组群6、 组群 7 和组群 9 互为姐妹种。但这一结果与以上领骨 的长度为原始特征构建的形态分类结果 (马春艳等, 2010)并不一致, 造成这种结果的原因可能与棱鳀 属鱼类各种间的生活习性趋同进化有关(马春艳等, 2010; Krück et al, 2013)。

马春艳等(2010)基于 $16 \mathrm{~S}$ rRNA基因序列探讨棱 鳀属鱼类的系统进化时发现中领棱鳀和黄吻棱鳀 的差异很小, 认为可能为同一种。本研究与该结果 相类似, 中领棱鳀和黄吻棱鳀聚类到一起, 且二者 间的遗传距离明显低于种间差异的一般标准。相似 的情况同样在鱚属 (Sillago) 鱼类中出现, Sillago analis和S. ciliata在外部形态上非常相似, 主要鉴别 特征存在一定的重叠, 且利用 $\mathrm{COI}$ 基因片段并不能 将二者区分开，种间遗传距离仅为 $0.12 \%$, 而同时 采用线粒体DNA和核基因分子标记能成功地区分
开两种鱚属鱼类，并支持形态上的分类结果 (Krück et al, 2013)。由此可见, 不能简单地将中领棱鳀和黄 吻棱鳀视为同一物种或两个种，仍需要结合更多分 子标记(如核基因分子标记RAG2等)对二者的分类 地位作进一步的探讨。而在中领棱鳀和黄吻棱鳀的 单倍型比较中可以看出, 二者都有独享单倍型, 是 否可以利用这些独享单倍型进行种类鉴定, 还需要 增加样品量来作进一步的验证。

综上所述, 本研究利用DNA条形码技术能成功 地鉴别出赤鼻棱鳀、汉氏棱鳀、杜氏棱鳀、长领棱 鳀, 结果与形态学分类一致, 表明DNA条形码能够 作为棱鳀属大部分鱼类快速鉴定的有效工具。而未 能成功地区分开中领棱鳀和黄吻棱鳀, 可以看出在 亲缘关系较近、分化时间较短的物种间, 由于其有 效的变异不能及时积累, 无法提供足够的信息, 导 致较为保守的基因(如COI)不再适合于物种间鉴别 (Summerer et al, 2001)。同样可以看出, GenBank中 棱鳀属鱼类的COI基因序列仍存在一定的问题, 其 中一些种类以错误学名进行提交, 同时还有一些未 知种名的序列存在。因此, 在今后的工作中有必要 加大棱鳀属鱼类样品的采集力度, 加强国际间的交 流，在寻找形态上分类鉴别特征的同时，评估其隐 存多样性水平。同时将传统的鱼类形态分类与DNA 条形码技术相结合, 才能更准确地鉴别鱼种, 进一 步确定其分类地位和系统发育关系, 为后续研究提 供科学依据。

\section{参考文献}

Bermingham E, McCafferty SS, Martin AP (1997) Fish biogeography and molecular clocks: perspectives from the Panamanian Isthmus. In: Molecular Systematics of Fishes (eds Kocher TD, Stepier CA), pp. 113-126. Academic Press, San Diego.

Bloom DD, Lovejoy NR (2012) Molecular phylogenetics reveals a pattern of biome conservatism in New World anchovies (family Engraulidae). Journal of Evolutionary Biology, 25, 701-715.

Chen WT, Ma XH, Shen YJ, Mao YT, He SP (2015) The fish diversity in the upper reaches of the Salween River, Nujiang River, revealed by DNA barcoding. Scientific Reports, Doi: $10.1038 /$ srep 17437.

Gao TX, Ji DP, Xiao YS, Xue TQ, Yanagimoto T, Setoguma T (2011) Description and DNA barcoding of a new Sillago species, Sillago sinica (Perciformes: Sillaginidae), from coastal waters of China. Zoological Studies, 50, 254-263.

Guo XW, Tang QS (2000) Consumption and ecological conversion efficiency of Thrissa kammalensis. Journal of Fish- 
eries of China, 24, 422-427. (in Chinese with English abstract) [郭学武, 唐启升 (2000) 赤鼻棱鳀的摄食与生态 转换效率. 水产学报, 24, 422-427.]

Hebert PDN, Cywinska A, Ball SL, deWaard JR (2003) Biological identifications through DNA barcodes. Proceedings of the Royal Society B: Biological Sciences, 270, 313-321.

Hyde JR, Vetter RD (2007) The origin, evolution, and diversification of rockfishes of the genus Sebastes (Cuvier). Molecular Phylogenetics and Evolution, 44, 790-811.

Jia XP, Li YZ, Li CH, Qiu YS, Gan JL (2004) Environment and Fishery Resources in the Exclusive Economic Zone and the Continental Shelf of South China Sea, pp. 339-542. Science Press, Beijing. (in Chinese) [贾晓平, 李永振, 李纯厚, 邱永松, 甘居利 (2004) 南海专属经济区和大陆架渔业生 态环境与渔业资源, 339-542. 科学出版社, 北京.]

Ko HL, Wang YT, Chiu TS, Lee MA, Leu MY, Chang KZ, Chen WY, Shao KT (2012) Evaluating the accuracy of morphological identification of larval fishes by applying DNA barcoding. PLoS ONE, 8, e53451.

Krück NC, Tibbetts IR, Ward RD, Johnson JW, Loh WKW, Ovenden JR (2013) Multi-gene barcoding to discriminate sibling species within a morphologically difficult fish genus (Sillago). Fisheries Research, 143, 39-46.

Lavoué S, Miya M, Nishida M (2010) Mitochondrial phylogenomics of anchovies (family Engraulidae) and recurrent origins of pronounced miniaturization in the order Clupeiformes. Molecular Phylogenetics and Evolution, 56, 480-485.

Li ZY, Jin XS, Zhuang ZM, Su YQ, Tang QS (2007) Food competition of Engraulis japonicus and Thryssa kammalensis from the southern Yellow Sea in spring. Journal of Fishery Sciences of China, 14, 630-636. (in Chinese with English abstract) [李忠义, 金显仕, 庄志猛, 苏永全, 唐启升 (2007) 南黄海春季鳀和赤鼻棱鳀的食物竞争. 中国水产 科学, 14, 630-636.]

Li Y, Song N, Khan FS, Yanagimoto T, Gao TX (2013) New evidence of morphological characters and DNA barcoding of Pampus argenteus (Euphrasen, 1788). Journal of Fisheries of China, 37, 1-9. (in Chinese with English abstract) [李 渊, 宋娜, Khan FS, 柳本卓, 高天翔 (2013) 银鲳形态特 征与DNA条形码研究. 水产学报, 37, 1-9.]

Li Y, Zhang LY, Song PQ, Zhong ZH, Zhang R, Gao TX, Lin LS (2014) A new record of Sillago species in Fujian coastal waters - Sillago sinica (Gao and Xue, 2011). Journal of Applied Oceanography, 33, 546-552. (in Chinese with English abstract) [李洣, 张丽艳, 宋普庆, 钟指挥, 张然, 高天翔, 林龙山 (2014) 福建省沿海鱚属(Sillago)鱼类新记录种 —中国鱚(Sillago sinica Gao and Xue, 2011). 应用海洋 学学报, 33, 546-552.]

Ma CY, Ma LB, Ni Y, Shen AL, Zhang Y, Zhang FY, Zhao YL (2010) Phylogenetic relationship of Thryssa inferred from morphologic characteristic and mitochondrial $16 \mathrm{~S}$ rRNA gene sequences. Journal of Fishery Sciences of China, 17, 471-476. (in Chinese with English abstract) [马春艳, 马凌波, 倪勇, 沈盎绿, 张永, 张风英, 赵云龙 (2010)
基于形态特征和线粒体 $16 \mathrm{~S}$ rRNA基因序列探讨棱鳀属的 系统进化. 中国水产科学, 17, 471-476.]

Shen YJ, Guan LH, Wang DQ, Gan XN (2016a) DNA barcoding and evaluation of genetic diversity in Cyprinidae fish in the midstream of the Yangtze River. Ecology and Evolution, Doi:10.1002/ece3.2060.

Shen YJ, Kang JL, Chen WT, He SP (2016b) DNA barcoding for the identification of common economic aquatic products in Central China and its application for the supervision of the market trade. Food Control, 61, 79-91.

Summerer M, Hanel R, Sturmbauer C (2001) Mitochondrial phylogeny and biogeographic affinities of sea breams of the genus Diplodus (Sparidae). Journal of Fish Biology, 59, 1638-1652.

Sun DR, Chen Z (2013) Fish Retrieval of South China Sea (Volume I), pp. 120-123. China Ocean Press, Beijing. (in Chinese) [孙典荣, 陈铮 (2013) 南海鱼类检索 (上册), 120-123. 海洋出版社, 北京.]

Ward RD, Zemlak TS, Innes BH, Last PR, Hebert PDN (2005) DNA barcoding Australia's fish species. Philosophical Transactions of the Royal Society B: Biological Sciences, 360, 1847-1857.

Whitehead PJP, Nelson GJ, Wongratana F (1988) FAO Species Catalogue, Vol. 7: Clupeoid Fishes of the World (suborder Clupeoidei): an Annotated and Illustrated Catalogue of the Herrings, Sardines, Pilchards, Sprats, Shads, Anchovies and Wolf-herrings (Part 2): Enggraulidae, Food and Agriculture Organization of the United Nations, Rome, pp. 305-579.

Zhang H, Zhang Y, Zhang ZH, Gao TX (2013) DNA barcodes of eight species in genus Sebastes. Biochemical Systematics and Ecology, 48, 45-50.

Zhang JB, Hanner R (2012) Molecular approach to the identification of fish in the South China Sea. PLoS ONE, 7, e30621.

Zhang SY (2001) Fauna Sinica: Osteichthyes, Acipenseriformes, Elopiforms, Clupeiformes, Gonorhynchiformes, pp. 137-147. Science Press, Beijing. (in Chinese) [张世义 (2001) 中国动物志·硬骨鱼纲: 鲟形目、海鲢目、鲱形目、 鼠鱚目, 137-147. 科学出版社, 北京.]

Zhou MY, Chen X, Yang SY (2015) Identification of several fish eggs and larvae by DNA barcoding in Xiamen Water. Marine Environmental Science, 34, 120-125. (in Chinese with English abstract) [周美玉, 陈骁, 杨圣云 (2015) 采 用DNA条形码技术对厦门海域鱼卵、仔稚鱼种类的鉴定. 海洋环境科学, 34, 120-125.]

Zhu YD. Wu HL, Jin XB, Meng QW, Liu J, Lian ZS, Shen GY, Huang ST, Chen HX, Zhang QY, Li WD, Wu XH (1984) Fish of Fujian (Vol. I), pp. 140-153. Fujian Science and Technology Publishing House, Fuzhou. (in Chinese) [朱 元鼎, 伍汉霖, 金金波, 孟庆闻, 刘基, 连珍水, 沈根媛, 黄少涛, 陈焕新, 张其永, 李婉端, 吴秀鸿 (1984) 福建 鱼类志 (上卷), 140-153. 福建科学技术出版社, 福州.]

(责任编委: 何舜平 责任编辑: 时意专) 